\title{
Bite force data suggests relationship between acrodont tooth implantation and strong bite force
}

\author{
Kelsey M Jenkins ${ }^{\text {Corresp., } 1}$, Jack O Shaw ${ }^{1}$ \\ ${ }^{1}$ Department of Earth and Planetary Sciences, Yale University, New Haven, United States of America \\ Corresponding Author: Kelsey M Jenkins \\ Email address: kelsey.jenkins@yale.edu
}

Extant and extinct reptiles exhibit numerous combinations of tooth implantation and attachment. Tooth implantation ranges from those possessing roots and lying within a socket (thecodonty), to teeth lying against the lingual wall of the jawbone (pleurodonty), to teeth without roots or sockets that are attached to the apex of the marginal jawbones (acrodonty). Attachment may be ligamentous (gomphosis) or via fusion (ankylosis). Generally speaking, adaptative reasonings are proposed as an underlying driver for evolutionary changes in some forms of tooth implantation and attachment. However, a substantiated adaptive hypothesis is lacking for the state of acrodont ankylosis that is seen in several lineages of Lepidosauria, a clade that is plesiomorphically pleurodont. The convergent evolution of acrodont ankylosis in several clades of lepidosaurs suggests a selective pressure shaped the evolution of the trait. We hypothesize that acrodont ankylosis as seen in Acrodonta and Sphenodon punctatus, is an adaptation either resulting from or allowing for a stronger bite force. We analyzed bite force data gathered from the literature to show that those taxa possessing acrodont dentition possess a stronger bite force on average than those taxa with pleurodont dentition. Dietary specialists with pleurodont dentition may also possess relatively high bite forces, though body size may also play a role in their ability to bite hard. Furthermore, our results have implications for the evolution of acrodont ankylosis and potential behaviors related to strong bite force that influenced the evolution of acrodonty within Acrodonta and Rhynchocephalia. 


\section{Bite Force Data Suggests Relationship between}

\section{Acrodont Tooth Implantation and Strong Bite Force}

3

4

5 Kelsey M. Jenkins ${ }^{1 *}$, Jack O. Shaw ${ }^{1}$

$6{ }^{1}$ Department of Earth and Planetary Sciences, Yale University, New Haven, Connecticut, USA

8 Corresponding Author:

9 Kelsey M. Jenkins*

Department of Geology and Geophysics, Yale University, New Haven, Connecticut, USA Email address: kelsey.jenkins@yale.edu

\section{Abstract}

Extant and extinct reptiles exhibit numerous combinations of tooth implantation and attachment. Tooth implantation ranges from those possessing roots and lying within a socket (thecodonty), to teeth lying against the lingual wall of the jawbone (pleurodonty), to teeth without roots or sockets that are attached to the apex of the marginal jawbones (acrodonty). Attachment may be ligamentous (gomphosis) or via fusion (ankylosis). Generally speaking, adaptative reasonings are proposed as an underlying driver for evolutionary changes in some forms of tooth implantation and attachment. However, a substantiated adaptive hypothesis is lacking for the state of acrodont ankylosis that is seen in several lineages of Lepidosauria, a clade that is plesiomorphically pleurodont. The convergent evolution of acrodont ankylosis in several 
23 clades of lepidosaurs suggests a selective pressure shaped the evolution of the trait. We

24 hypothesize that acrodont ankylosis as seen in Acrodonta and Sphenodon punctatus, is an

25 adaptation either resulting from or allowing for a stronger bite force. We analyzed bite force data

26 gathered from the literature to show that those taxa possessing acrodont dentition possess a

27 stronger bite force on average than those taxa with pleurodont dentition. Dietary specialists with

28 pleurodont dentition may also possess relatively high bite forces, though body size may also play

29 a role in their ability to bite hard. Furthermore, our results have implications for the evolution of

30 acrodont ankylosis and potential behaviors related to strong bite force that influenced the

31 evolution of acrodonty within Acrodonta and Rhynchocephalia.

\section{Introduction}

Acrodont tooth implantation, where the tooth rests at the summit of the tooth-bearing

bone, evolved multiple times within Lepidosauria. It appears at least twice within squamate

reptiles, as seen in Acrodonta (Romer, 1956) and Trogonophidae (Gans, 1960), and once within

Rhynchocephalia (Jenkins et al., 2017) (Fig. 1). In Acrodonta and Sphenodon punctatus, the only

37 living representative of Rhynchocephalia, the dentition is strongly ankylosed (i.e., fused) via the

adjacent bone. In those taxa, teeth and surrounding tissues have been investigated thoroughly via

histological studies (Cooper \& Poole, 1973; Smirina \& Ananjeva, 2007; Kieser et al., 2009,

2011; Haridy, 2018), CT data (Dosedělová et al., 2016), and in vitro staining (Buchtová et al.,

2013; Salomies et al., 2019). However, the evolution of acrodont tooth implantation is seldom

discussed in an adaptive context.

Smith (1958) suggested that acrodonty is a trait associated with anchoring a permanent

44 dentition, and possibly inhibiting tooth replacement. Presently, this remains the only functional

45 hypothesis associated with acrodont dentition. Furthermore, growing body of work shows that 
46 anchoring dentition does not inhibit tooth replacement, and anchoring occurs after tooth

47 generation and replacement cease (Handrigan \& Richman, 2010; Buchtová et al., 2013;

48 Dosedělová et al., 2016; Haridy, 2018; Salomies et al., 2019). Smith (1958) also suggested that 49 thecodonty, where the tooth sits within a socket, is associated with permanent dentition. While 50 that is the case in mammals, it is well known that several reptilian lineages and early synapsids 51 possess thecodont implantation and replace their teeth with some regularity (e.g., Edmund, 1960, 52 1962; Gaengler, 2000; McIntosh et al., 2002; LeBlanc et al., 2017; D’Emic et al., 2019; Snyder 53 et al., 2020). Unlike acrodont dentition, thecodonty is not necessarily associated with ankylosis 54 and may attach to the surrounding bone ligamentously, termed gomphosis (Osborn, 1984). There are a suite of traits commonly associated with acrodont tooth implantation, most

56 57 typically reduced tooth counts and severe tooth wear (Augé, 1997; Haridy, 2018). However, those characters are not necessarily associated with every taxon exhibiting acrodont tooth implantation. Though some have noted a loss of the alveolar foramen in the teeth of acrodontan squamates, using this trait to diagnose those taxa (Zaher \& Rieppel, 1999), it was later found that Pogona vitticeps possesses nutrient foramina supplying the pulp cavities (Haridy, 2018). A slowing or lack of tooth replacement, called monophyodonty, is also commonly associated with acrodont tooth implantation (Smith, 1958; Cooper et al., 1970), although exceptions do exist (Gow, 1977; Haridy, LeBlanc \& Reisz, 2018). Even with monophyodont dentition, additional teeth are typically still added to the posterior end of the tooth row throughout ontogeny, as is the plesiomorphic condition within Reptilia (Robinson, 1976; Gow, 1977; Rieppel, 1992; Reynoso, 2003).

As individuals of Acrodonta and Sphenodon punctatus age, the boundary between tooth and bone becomes difficult to determine externally (Fig. 2). This is a result of alveolar bone 
69 growing to surround the outer portion of the tooth through ontogeny (Buchtová et al., 2013;

70 Haridy, 2018). This feature has caused some to erroneously propose that S. punctatus lacks teeth

71 entirely, instead possessing a serrated jawbone (Mlot, 1997). Severe wear may obscure the

72 anterior dentition in older, acrodont, monophyodont lepidosaurs, and in some cases the teeth may

73 be worn to the point where the bone itself forms the occlusal surface in the anterior portion of the

74 mouth (Robinson, 1976). To resist wear as the reptile ages, the pulp cavity infills with bone and

75 secondary dentine as seen in members of Acrodonta (Throckmorton, 1979; Smirina \& Ananjeva,

76 2007; Dosedělová et al., 2016; Haridy, 2018) or secondary dentine and pulp-stones as seen in $S$.

77 punctatus (Kieser et al., 2009).

78 The ancestral state of tooth implantation and attachment in the reptilian lineage is thought

79 to involve a tooth set in a shallow socket (i.e., subthecodonty) attached via ankylosis (Bertin et

80 al., 2018), though some of the most basal reptiles exhibit pleurodont tooth implantation (LeBlanc

$81 \&$ Reisz, 2015). Furthermore, the periodontal ligament is likely ancestrally present in all

82 amniotes (LeBlanc et al., 2016). However, reptiles have since explored many forms of tooth

83 implantation (acrodonty, pleurodonty, and thecodonty) and attachment (ankylosis and

84 gomphosis) in varying combinations. Adaptive interpretations are occasionally used to explain

85 why reptiles may stray from the ancestral state within their respective clades (Smith, 1958;

86 Noble, 1969; Osborn 1984). Other adaptations for attachment include dentine infoldings, called

87 plicidentine, which evolved independently multiple times within Reptilia, and it is interpreted to

88 be a mechanism to strengthen tooth attachment in kinetic-feeding predators by increasing the

89 surface area for attachment (Preuschoft et al., 1991; Maxwell, Caldwell \& Lamoureux, 2011;

90 Brink et al., 2014; MacDougall et al., 2014). Even the loss of teeth may be associated with the

91 evolution of other adaptive structures, like a keratinous beak (Davit-Béal, Tucker \& Sire, 2009). 

pleurodont ankylosis, seen in basal members of both Squamata and Rhynchocephalia (e.g.,

94 Evans, 1980; Whiteside, 1986; Reynoso, 1998; Simões et al., 2018). Additionally, the 95 lepidosauromorphs Marmoretta and Sophineta possess pleurodont tooth implantation (Evans, 1991; Evans \& Borsuk-Białynicka, 2009). The evolution of acrodont ankylosis accompanied by

97 bone and secondary dentine deposition, as seen in Acrodonta and Sphenodon punctatus, lacks 98 any adaptive hypothesis. Here we suggest that this combination of traits is an adaptation associated with strong bite force. Anecdotal evidence suggests that acrodont taxa possess a strong bite: S. punctatus is said to possess a painful and 'vice-like' bite (Robb, 1977; Daugherty and Cree, 1990), and one of the authors (KMJ) notes from personal experience that the veiled chameleon, Chamaeleo calyptratus, also possesses a painful bite and is reluctant to release its victim. Bite-force analyses also indicate agamids have a stronger bite than $S$. punctatus, relative to body size (Schaerlaeken et al., 2008; Jones and Lappin, 2009).

The literature concerning bite force in lepidosaurs is numerous and implies a multitude of benefits for increased bite force. For instance, increase bite force is thought to improve prey capture and handling in lepidosaurs, particularly for the consumption of hard-bodied prey (Herrel et al., 1999; Herrel et al., 2001; Verwaijen, Van Damme \& Herrel, 2002; Meyers et al., 2018). High bite force may also aid in territory defense and dominance (Herrel, Meyers \& Vanhooydonck, 2001; Lailvaux et al., 2004; Huyghe et al., 2005; Husak et al., 2006; Jones \&

111 Lappin, 2009), and mating success (Lappin \& Husak, 2005; Husak et al., 2009; Herrel et al., 112 2010). Higher bite force in lizards is often accompanied by skeletal correlates in the cranium and 113 increased mass of the adductor musculature compared to those with lower bite force (Herrel, 114 McBrayer \& Larson, 2007; Fabre et al., 2014). Cranial kinesis also plays a strong role in bite 
115 force, with a more rigid or akinetic skull being more capable of producing a strong bite

116 (Erickson, Lappin \& Vliet, 2003; Wroe, McHenry \& Thomason, 2005; Tseng \& Binder, 2010;

117 Cost et al., 2020). Thus, the varying degrees of kinesis in lizard and tuatara skulls can certainly

118 impact bite force within Lepidosauria (Frazzetta, 1962).

119 We suggest that acrodont tooth implantation is yet another skeletal trait associated with

120 bite force. We hypothesize that taxa possessing acrodont dentition also possess a higher bite

121 force, compared to those with pleurodont dentition, relative to body size. Furthermore, the

122 accompanied bone deposition around the base of the dentition may also assist in resisting strong

123 biting. In order to test our hypothesis, we analyzed bite force data based on a comprehensive

124 literature review among lepidosaurian taxa. We found that size-normalized bite force was

125 significantly greater in acrodont lepidosaurs than pleurodont lepidosaurs. Furthermore, we

126 discuss the evolution of acrodont ankylosis within an adaptive context in response to high bite

127 force.

128 Materials \& Methods

129 To assess the relationship between lepidosaurian bite force and tooth implantation, we

130 analyzed previously recorded bite force data. We collected mean snout-vent length (SVL), mean

131 head depth (HD), and mean bite force (BF) measurements from thirty-nine peer-reviewed papers

132 (Supplementary Files). Though bite force can be measured via different methods (see Lappin \&

133 Jones, 2014), all studies analyzed here measured the orthal bite. Following previous studies

134 (Erickson et al., 2004; Wroe, McHenry \& Thomason, 2005; Sellers et al., 2017) we analyzed

135 log-transformed measurements (analyses of non-transformed data provided in supplement).

136 We focused on the relationship between SVL and BF, as SVL is the most commonly

137 reported measure of size in reptiles (Fig. 3). However, many squamate reptiles possess elongate 
138 body forms that are not necessarily correlated to cranial allometry, and thus may not strongly

139 correlate with bite force. Because of this, we also standardized by head depth in separate

140 analyses (Fig. 4). Multiple studies evaluating lepidosaurian bite force suggest that head depth is a

141 good predictor of bite force because it accommodates the adductor musculature (Herrel, de

142 Grauw \& Lemos-Espinal, 2001; Lappin, Hamilton \& Sullivan, 2006; McBrayer \& Anderson,

143 2007; Herrel et al., 2010). Tooth implantation was assessed by the authors.

144 To examine differences in bite force between acrodont and pleurodont taxa, analyses of

145 covariance (ANCOVA) were performed using both size variables (log-SVL and log-HD) as

146 covariates. To further compare bite force across taxa of significantly different body masses, we

147 calculated normalized bite force (NBF) as the residuals of a linear regression fit to (1) log-SVL

148 and $\log -\mathrm{BF}$ or (2) $\log -\mathrm{HD}$ and $\log -\mathrm{BF}$. We refer to these values as SVL-NBF and HD-NBF,

149 respectively. Differences in NBF between tooth implantation groups were then assessed using

150 Kolmogorov-Smirnov (KS) tests.

151 To evaluate the proportion of the lepidosaurian tree that has been examined in terms of

152 bite force, we tallied all known publications that record lepidosaurian bite force (Fig. 5;

153 Supplementary Files). This includes those publications that were not included in the initial

154 analyses that compare bite force between acrodont and pleurodont taxa due to a lack of raw bite

155 force data or a lack of necessary variables (i.e., SVL). Seventeen lepidosaurian families were

156 represented by bite force data, including four acrodont families and 13 pleurodont families.

157 Dactyloidae was represented by the most species $(n=49)$, while the families of Sphenodontidae,

158 Varanidae, and Trogonophidae were only represented by single species.

159 Results 
Bite force is higher in acrodont taxa than in pleurodont taxa after accounting for size

161

162

163

164

165

166

167

168

169

170

171

172

173

174

175

176

177

178

179

180

181

182

differences (Fig. 3B \& 4B). Raw bite force values ranged from 0.3 to 409.3 Newtons, SVL

ranged 13.0-389.0 $\mathrm{mm}$, and HD ranged 4.0-55.5 $\mathrm{mm}$. SVL-NBF ranged -2.17 to 1.76 , whereas

HD-NBF ranged -2.35 to 1.61 (Supplementary Files). ANCOVAs of tooth implantation type and

SVL and of tooth implantation type and HD have low p-values ( 0.064 and 0.0023 , respectively)

indicating differences in bite force between the acrodont and pleurodont taxa after accounting for

SVL and HD. According to one-sided KS tests, acrodont SVL-NBF and HD-NBF values were

significantly greater than those of pleurodonts. Linear regressions of log-SVL and log-BF, and of $\log$-HD and log-BF were statistically significant and exhibited positive slopes (p-value $<0.05)$.

Correlations were stronger between $\log -\mathrm{SVL}$ and $\log -\mathrm{BF}$ (Adj R-square $=0.71$ ), compared to $\log$-HD and log-BF (Adj R-square = 0.69).

The only direct comparisons that could be made for both tooth implantation categories and diet were for insectivory and herbivory (Fig. 3C \& 4C). According to one-sided KS tests, SVL-NBF and HD-NBF values were significantly greater for insectivorous acrodonts compared to insectivorous pleurodonts ( $\mathrm{p}$-value $<0.05$ ). Overall, pleurodont insectivores exhibited a large range of NBF values (Fig. 3C). Although acrodont insectivores seemingly also exhibited a wide range of SVL-NBF values, this is influenced by the elongate body plan seen in on taxon, Trogonophis wiegmanni, in which head dimensions do not correlate strongly with SVL (Fig. 3C). HD-NBF values for acrodont insectivores range less than the SVL-NBF values of the same group (Fig 4C). A direct comparison of herbivorous acrodonts and pleurodonts reveals a lack of significant difference between the NBF vales of the two groups, according to one-sided KS tests. While direct comparisons between tooth implantation types and other diets are not possible using the available data, we also found that pleurodont frugivores exhibit the highest median NBF 
183 values whereas durophagous pleurodonts exhibit the lowest median NBF values, although the

184 latter is based on a small number of measurements $(n=2)$.

185 Low SVL-NBF values in Trogonophidae indicate that the clade exhibits lower bite force 186 than expected for SVL (Fig. 3D). These values were much lower than for other acrodont taxa, 187 dramatically impacting the range and median SVL-NBF values for acrodonts. This trend is not 188 present in HD-NBF, in which Trogonophidae exhibits the highest median bite force (Fig. 4D). 189 Excluding Trogonophidae, Chamaeleonidae exhibited the highest SVL-NBF and HD-NBF 190 values among acrodonts. Among pleurodont taxa, Lacertidae exhibits the largest range of NBF 191 values for both SVL and HD. Anguidae exhibits the greatest median values for HD-NBF. 192 Iguanidae exhibits the greatest median SVL-NBF values. Both Gekkonidae and Scincidae exhibit 193 low median SVL-NBF values, but data does not exist for either clade for HD-NBF.

194 Phrynosomatidae exhibits the lowest median HD-NBF values.

\section{Discussion}

Thus far, anatomical research related to bite force in lepidosaurian reptiles has focused

197 primarily on cranial musculature and skeletal dimensions, namely head depth, length, and width.

198 However, teeth are more intimately associated with biting and oral processing than the 199 aforementioned elements. Dental morphology is often adapted for diet, with generalists 200 possessing a more unspecialized dentition and specialists often possessing more unique tooth 201 morphologies (e.g., Estes \& Williams, 1984), though true specialists within lizards are rare and 202 diets are often quite varied (Greene, 1982; Schaerlaeken et al., 2012). It should come as no 203 surprise that tooth implantation and attachment are also shaped by oral processing capabilities. 204 For example, multiple functional hypotheses exist for the evolution of thecodonty and associated 205 periodontal ligament: a means of shock absorption and dissipation (Noble, 1969; Picton, 1989; 
206 McIntosh et al., 2002; Bosshardt et al., 2008), facilitation of post-eruption tooth movement 207 (Osborn, 1984; Bosshardt et al., 2008), creation of a sensory system to allow the jaws to 208 reposition during mastication (Bosshardt et al., 2008), flexible attachment of tooth to bone 209 (Leblanc \& Reisz, 2013), and for anchoring permanent dentition in mammals as mentioned 210 above (Smith, 1958). Similar hypotheses for the evolution of acrodont ankyloses in reptiles are 211 lacking. Here we show that there is a relationship between acrodont ankylosis and high bite 212 force. However, there is still the question of whether (1) acrodont ankylosis developed due to 213 strong bite force, or if (2) strong bite force evolved as a consequence of acrodont ankylosis. 214 In the first scenario, acrodont ankylosis is a response to increased bite force by further 215 securing the tooth to the bone as a means to resist failure during strong biting. Previous work 216 shows that a stouter, blunter tooth, like that of acrodont taxa, is more resistant to failure under 217 increased bite forces (Lucas \& Luke, 1984; Evans \& Sanson, 1998; Jones, 2006), compared to a 218 more columnar or piercing tooth seen in most pleurodont lepidosaurs which is prone to breakage 219 under increased forces (Evans \& Sanson, 1998; Erickson, Lappin, \& Vliet, 2003). We suggest 220 that the ankylosis and bone deposition seen in Acrodonta and Sphenodon punctatus that 221 accompanies the typical acrodont tooth morphology would also aid in resisting tooth failure.

222 Simply put, a fused tooth is sturdier than a tooth attached via soft tissue. The specific 223 combination of morphology, implantation, and attachment seen in Acrodonta and S. punctatus 224 allows for a tooth that is most resistant to failure. However, that is not to say that breakage is 225 impossible in taxa possessing acrodont ankylosis. The extremely strong adherence of teeth can 226 result in the occasional breakage of both tooth and bone (Dosedělová et al., 2016). Perhaps this is 227 due to the more brittle nature of such a strongly fused tooth, compared to a ligamentous 228 attachment in which the tooth is better cushioned during feeding (Noble, 1969; Picton, 1989; 
229 McIntosh et al., 2002; Bosshardt et al., 2008). Though pleurodont dentition in other lizards is 230 also ankylosed, most lack the bone growth that adheres the tooth to the jaw that is seen in 231 Acrodonta and S. punctatus. However, there are a few notable squamates without acrodont 232 dentition that possess large deposits of boney tissue around the base of the teeth (e.g., Caldwell, 233 1999; Zaher \& Rieppel, 1999).

234 In the second scenario, strong bite force is a response to acrodont ankylosis. Acrodonta 235 and Sphenodon punctatus are monophyodont and exhibit severe wear, particularly in the anterior dentition as seen in older individuals. Although those individuals have extremely worn teeth, they still manage to capture and consume prey. If the dentition is severely worn due to a lack of replacement, increased bite force would be crucial in allowing the jaws to clamp tightly onto prey. However, this could be a factor of monophyodonty instead of acrodonty alone. Nonetheless, older individuals with few functional teeth can still forage and consume as needed.

241 If strong bite force in Acrodonta and S. punctatus evolved as a mechanism to aid in territory 242 defense or increased mating success (opposed to prey handling), an older animal may be 243 successful even though it possesses severely worn teeth. At this time, we cannot favor one 244 hypothesis over another. It is also possible that different lineages acquired acrodont ankylosis 245 under either scenario. lepidosaurs possessing acrodont ankylosis fill various dietary niches ranging from insectivory to

250 herbivory (Fig. $3 \& 4$ ), calling to question the idea that the combined traits are currently acting as 251 an adaptation for similar diets. Furthermore, extant squamates eating hard-shelled organisms, 
252 such as Varanus niloticus and Tiliqua scincoides (Rieppel, 1979; Estes \& Williams, 1984), and

253 high-fibered fruit, such as Gallotia galloti (Valido, Nogales, \& Medina, 2003), possess

254 pleurodont dentition, so it cannot be assumed that acrodont ankylosis evolved as a means to

255 process tough foods (or that it is the only means by which to process tough foods, see section

256 below). We also doubt that acrodont ankylosis first arose in response to a particular diet,

257 because basal rhynchocephalians possessing acrodont dentition were likely insectivorous (Evans,

258 1980; Fraser \& Walkden, 1983; Whiteside, 1986). Insectivory is also widespread among extant

259 squamates, which mostly possess pleurodont dentition, so it seems unlikely that the initial

260 evolution of acrodont ankylosis would be strongly influenced by an insectivorous diet.

261 Acrodonty remained widespread as rhynchocephalians diversified to fill various dietary niches

262 (Jones 2006, 2009), so it seems unlikely that acrodont ankylosis evolved in response to any

263 particular diet. Possessing firmly ankylosed acrodont dentition in conjunction with a higher bite

264 force does allow access to harder foodstuffs, but it cannot be assumed to be the sole reason for

265 the evolution of acrodont ankylosis.

266 The second hypothesis is that shared oral mechanics shaped the evolution of acrodont

267 ankylosis, implying a mechanical constraint influenced the evolution of the trait. Previous bite

268 force measurements of S. punctatus only measure the orthal bite, and not the force of the

269 propalinal stroke (Schaerlaeken et al., 2008; Jones and Lappin 2009). While both squamates and

270 Sphenodon punctatus are capable of orthal shearing, S. punctatus is well-known for possessing

271 an akinetic skull and using propalinal jaw movement, where the lower jaw moves in an anterior-

272 posterior motion (Robinson, 1976; Gorniak et al, 1982; Cartland-Shaw et al., 1998; Jones, 2008).

273 This is in contrast with most squamates which possess kinetic skulls and typically favor

274 streptostyly in order to move the lower jaw in a fore and aft motion (Evans, 2008). The rigidity 
275 afforded by an akinetic skull does allow for a relatively stronger orthal bite in Sphenodon

276 punctatus than most lizards, and kinesis is thought to reduce the strength of a bite though

277 allowing for improved prey capture and handling. However, the acrodont taxa examined here

278 possess some of the least kinetic skulls among squamates (Iordansky, 1990; Arnold, 1998),

279 possibly improving the capability of a strong bite. Though the acrodont taxa examined here do

280 possess more rigid skulls, allowing for stronger biting, there does not seem to be a shared oral

281 mechanism that would influence the evolution of acrodont ankylosis.

282 It is worth noting that not all acrodontan lizards possess a fully acrodont dentition.

283 Agamid lizards possesses a dentition that is anteriorly pleurodont and posteriorly acrodont

284 (Cooper et al., 1970). While the pleurodont dentition still regularly replaces, the acrodont

285 dentition does not. In those taxa, tooth morphology varies greatly along the tooth row, with the

286 anterior pleurodont teeth being more slender and sharp. Bite force decreases as gape angle

287 increases (e.g., Dumont \& Herrel, 2003), thus the anterior pleurodont dentition is consistently

288 subjected to less force than the posterior acrodont dentition and need not be as 'reinforced' as the

289 posterior acrodont dentition. This combination of factors (tooth morphology, implantation,

290 attachment, and relative position) suggests that the anterior and posterior portions of the mouth

291 play differing roles in food processing. While the anterior dentition may be better suited for

292 grasping and piercing, the posterior dentition is more suited for crushing. Chameleons do not

293 possess such a marked difference in tooth morphology, implantation, and attachment as agamid

294 lizards. This could reflect a difference in diet as well as a difference in the nature of lingual prey

295 apprehension between agamids and chameleons. Though both use lingual prey apprehension to

296 capture food, chameleons can ballistically project their tongues a considerable distance in

297 comparison to agamids (Meyers \& Nishikawa, 2000). This projection could certainly affect, or 
298 potentially damage, the anterior dentition if it were of a more slender morphology and not 299 strongly ankylosed to the jaw bone.

Of the taxa that were examined in previous publications, fewer species of lepidosaurs

301

302

303

304

305

306

307

308

309

310

311

312

313

314

315

316

317

318

319

320

with acrodont tooth implantation have been studied in regard to bite force in comparison to those with pleurodont implantation (Fig. 5). Of the pleurodont taxa, 49 species of Anolis lizards (Dactyloidae) were the subjects of 20 publications that record bite force alone. Those taxa make up the largest proportion of pleurodont taxa analyzed here. The large number of Anolis-based studies is partly because they are speciose and represent a particularly important model taxon for ecological and evolutionary studies in the Americas. Conversely, only 16 unique species of acrodont lepidosaurs belonging to four separate families are the subject of 17 publications that record bite force. Only 16 families of squamate lizards have been subjected to bite force analyses, which leaves a large portion of the squamate line understudied (Fig. 5). Further examination of bite force and diet across Lepidosauria may enforce our hypothesis while also revealing other ecological and evolutionary trends.

\section{Can acrodont ankylosis be reversed?}

The transition from pleurodont to acrodont tooth implantation occurred independently several times within Lepidosauria (Acrodonta, Trogonophidae, Rhynchocephalia) and it is even seen in stem lepidosauromorphs (Sobral, Simões \& Schoch, 2020), but only in Acrodonta and Rhynchocephalia is the tooth-bone boundary difficult to detect upon initial inspection. Stem Acrodonta do not possess the extensive bone deposition that accompanies ankylosis, nor do they possess the apical tooth implantation that is seen in the crown group, although the roots of the teeth are much shorter than most other iguanian lizards and possess a relatively increased degree of ankylosis (Simões et al., 2015). All crown acrodontans possess some degree of acrodont tooth 
321 implantation accompanied by ankylosis and bone deposition. Within that clade, acrodont

322 ankylosis may appear to be a fixed trait that lacks the plasticity to explore other forms of tooth

323 implantation and attachment. However, developmental evidence suggests that the tissues that

324 promote tooth formation and replacement in some acrodontan lizards is still present (Salomies et 325 al., 2019), thus there is potential for the reversal of monophyodonty, and by extension, strong 326 ankylosis. The more likely explanation is that there has been no selective pressure acted upon 327 tooth implantation, attachment, and replacement within Acrodonta that would drive members of 328 the clade away from acrodont ankylosis since it initially evolved. While this may imply a 329 potentially adaptive circumstance to the initial evolution of this trait, it cannot be excluded that 330 this trait may no longer act as an adaptation in extant Acrodonta.

331 Acrodont ankylosis is persistent within Rhynchocephalia, but several transitions in tooth 332 implantation occurred from an initially acrodont state (Jenkins et al., 2017). Ankylosphenodon 333 pachyostosus possesses 'ankylothecodont' dentition, in which the tooth has deeply implanted 334 roots, but is nonetheless ankylosed to the surrounding bone (Reynoso, 2000). One genus, 335 Sapheosaurus, potentially lacks marginal dentition, although it is unknown if this is due to 336 extensive wear or if this taxon was truly edentulous (Cocude-Michel, 1963). The teeth of 337 Priosphenodon avelasi possesses a more complex dentition, with teeth set within a shallow 338 socket and periodontium holding adjacent teeth together (LeBlanc et al., 2020). The tooth plates 339 seen in Oenosaurus muelheimensis also represent an interesting derivation from the typical tooth 340 seen within Rhynchocephalia (Rauhut et al, 2012). Nonetheless, the tooth implantation of $O$.

341 muelheimensis was described as acrodont. Although acrodonty is widespread within

342 Rhynchocephalia, tooth implantation seems to be a more plastic trait within this clade than it is

343 within Acrodonta. Though implantation and attachment within Rhynchocephalia may vary, 
344 monophyodonty seems to be persistent in derived rhynchocephalians. However, the most basal

345 rhynchocephalian known, Gephyrosaurus bridensis, did replace its pleurodont teeth regularly

346 much like pleurodont lizards (Evans, 1985).

\section{More than One Way to Crush a Clam - Durophagous Pleurodonts}

Aside from the state of acrodont ankylosis, other forms of dentition may act in a similar

349 function. Many suggest that the molariform teeth of durophagous lizards are well equipped for

350

withstanding strong, crushing bites necessary for ingesting molluscs and other hard-shelled prey

351

352

353

354

355

356

357

358

359

360

361

362

363

364

365

366

(Evans \& Sanson, 1998; Schaerlacken et al., 2012). Dracaena guianensis and Tiliqua scincoides

(both pleurodont) are the only durophagous taxa for which SVL-NBF data could be analyzed

within the present study. D. guianensis is the only durophagous representative for HD-NBF.

Though sample size is limited, those durophagous taxa showed the lowest median NBF values

(Fig 3 \& 4). However, raw data reports a bite force of $383.3 \mathrm{~N}$ for D. guianensis, which is among the higher raw bite force values recorded. Given the general increase in bite force with size, the larger overall size of D. guianensis compared to most taxa within the dataset (Supplementary

Files) is likely the primary driver of its high bite force, although other morphological, evolutionary, and ecological factors may play supporting roles. Nonetheless, even under higher bite forces, their teeth are pleurodont, suggesting that not all dentition need evolve into acrodont ankylosis in order to withstand high bite forces.

Varanus niloticus has been subjected to several studies concerning its dental morphology and cranial kinematics (Rieppel, 1979; Rieppel \& Labhardt, 1979; Condon, 1987; D’Amore, 2015). $V$. niloticus undergoes an ontogenetic change in dentition, with juveniles possessing more slender teeth that later transition to more bulbous molariform dentition (Rieppel \& Labhardt, 1979; D’Amore, 2015). This ontogenetic shift in tooth morphology is often attributed to an 
367 ontogenetic shift in diet, with adults consuming larger proportions of molluscs and crabs

368 (Rieppel \& Labhardt, 1979; Luiselli, Akani \& Capizzi, 1999; Lenz, 2004). However, some

369 suggest there is no evidence for a dietary shift within this species (Bennett, 2002), while others

370 show that certain populations consume snails and crabs while other populations do not consume

371 hard-bodied prey (Losos \& Greene, 1988). Other species of Varanus without specialized

372 dentition are also known to eat hard-bodied prey, such as turtles and crabs (Losos \& Green,

373 1988). We might presume $V$. niloticus has a relatively high raw bite force, allowing for the

374 consumption of hard-bodied prey, but how that relates to body size and how it compares to the

375 bite forces of other varanids is unknown.

376 Acrodonty in Amphisbaenia

377 We know little about tooth attachment in Trogonophidae, though the clade is thought to

378 be acrodont and the teeth are likely ankylosed (Gans, 1960; Gans \& Montero, 2008). The

379 relatively lower bite force seen in $T$. wiegmanni compared to other acrodont taxa seen in our

380 results was likely impacted by the fact that $T$. wiegmanni is an elongate, serpentine-like form.

381 Because of that, using SVL to standardize our results may not be meaningful in the case of this

382 taxon. However, the other taxa examined in this study are not impacted by extremely elongate

383 body plans. When bite-force is standardized by head depth, the same trend of greater acrodont

384 bite force is more apparent for T. wiegmanni. Further work on the dentition of this clade would

385 clarify if it too possesses strong ankylosis or bone deposition around the base of the dentition like

386 that of Acrodonta and Sphenodon punctatus.

387 Trogonophidae is the only clade within Amphisbaenia to evolve acrodont tooth

388 implantation. However, other amphisbaenians possess teeth with roots of varying lengths.

389 Overall, amphisbaenians possess shorter roots than what is seen in most iguanians and geckos. 
390 Tooth implantation in amphisbaenians is often described as 'subacrodont' or 'subpleurodont' to

391 denote the stray from the 'typical' pleurodont tooth implantation seen in most other squamates

392 (Estes, 1975; Yatkola, 1976; Sullivan, 1985; Charig and Gans, 1990; Kearney, Maisano \& Rowe,

393 2004; Gans and Montero, 2008; Longrich et al., 2015; Čerňanský, Klembara \& Müller., 2016).

394 The evolution of tooth implantation and attachment in Amphisbaenia has not been explored

395 further, but the trend towards dentition with shorter roots is intriguing. Bite-force experiments

396 conducted on amphisbaenians could address if the evolution of acrodonty within the clade is

397 related to high bite force and diet. However, we cannot exclude the evolution of acrodont tooth

398 implantation within Amphisbaenia may have arose for other reasons, such as limited jaw space.

\section{Conclusions}

400

401

402

404

405

406

407

408

409

410 Furthermore, these dental traits may have evolved convergently in response to different selective

411 pressures depending on the clade. Acrodont ankylosis accompanied by bone deposition may be

412 fixed traits in Acrodonta, which has not explored other forms of tooth implantation and 
413 attachment. However, rhynchocephalians were able to explore other forms of tooth implantation

414 throughout their evolutionary history, though are largely monophyodont.

415 Acrodont ankylosis is not the only form of tooth implantation and attachment potentially

416 associated with higher bite forces. Durophagous squamates, though pleurodont, often possess

417 molariform tooth morphologies that are also able to withstand increased bite force. In the present

418 study, it appears that higher bite force is likely related to larger body size for these specialists.

419 However, bite force and its relationships with tooth morphology requires further study in

420 durophagous squamates as well as other dietary specialists. Most of the taxa analyzed were

421 insectivorous generalists, though carnivorous acrodonts, herbivorous acrodonts and pleurodonts,

422 and durophagous, frugivorous, and omnivorous pleurodonts were also included. The array of

423 diets seen in extant acrodont taxa suggests that if acrodont ankylosis evolved as an adaptation to

424 a particular diet, it may no longer act in an adaptive capacity for a specific diet. We encourage

425 further study on dietary specialists, for greater variation in bite force may exist among Squamata,

426 with subsequent implications for dental evolution in terms of tooth implantation, attachment,

427 replacement, and morphology.

428

429 Acknowledgements

We thank D. Meyer, M. Fabbri, and R. Armfield for providing helpful comments on an

432 Yale Peabody Natural History Collections. We thank the three reviewers of this manuscript, Y.

433 Haridy, A.R.H. LeBlanc, and K.S. Brink, who provided helpful comments and additional

434 suggestions that greatly enhanced this work. 


\section{References}

436 Arnold, E.N. 1998. Cranial kinesis in lizards: variations, uses, and origins. Evolutionary Biology

437

438

439

440

441

442

443

444

445

446

447

448

449

450

451

452

453

454

455 $30: 323-357$.

Augé, M. 1997. A consideration of the phylogenetic significance of acrodonty. Herpetological Journal 7:111-113.

Bennett, D. 2002. Diet of juvenile Varanus niloticus (Sauria: Varanidae) on the Black Volta River in Ghana. Journal of Herpetology 36:116-117.

Bertin, T.J.C., B. Thivichon-Prince, A.R.H. LeBlanc, M.W. Caldwell, and L. Viriot. 2018. Current Perspectives on tooth implantation, attachment, and replacement in Amniota. Frontiers of Physiology 6:1-20 DOI: 10.3389/fphys.2018.01630

Bosshardt, D.D., M. Bergomi, G. Vaglio, and A. Wiskott. 2008. Regional structural characteristics of bovine periodontal ligament samples and their suitability for biomechanical tests. Journal of Anatomy 212:319-329 DOI: 10.1111/j.14697580.2008.00856.x

Brink, K.S., A.R.H. Leblanc, and R.R. Reisz. 2014. First record of plicidentine in Synapsida and patterns of tooth root shape change in Early Permian sphenacodontians. Naturwissenschaften 101:883-892 DOI: 10.1007/s00114-014-1228-5

Buchtová, M., O. Zahradníček, S. Balková, and A.S. Tucker. 2013. Odontogenesis in the veiled chameleon (Chamaeleo calyptratus). Archives of Oral Biology 58:118-133.

Caldwell, M.W. 1999. Description and phylogenetic relationships of a new species of Coniasaurus Owen, 1850 (Squamata). Journal of Vertebrate Paleontology 19:438-455. 
456 Cartland-Shaw, L.K., A. Cree, C.M. Skeaff, N.M. Grimmond. 1998. Differences in dietary and 457 plasma fatty acids between wild and captive populations of a rare reptile, the tuatara 458 (Sphenodon punctatus). Journal of Comparative Physiology B 168:569-580.

459 Čerňanský, A., J. Klembara, and J. Müller. 2016. The new rare record of the late Oligocene 460 lizards and amphisbaenians from Germany and its impact on our knowledge of the 461 European terminal Palaeogene. Palaeobiodiversity and Palaeoenvironments 96:559-587. 462 Charig, A.J., and C. Gans. 1990. Two new amphisbaenians from the Lower Miocene of Kenya. 463 Bulletin of the British Museum of Natural History 46:19-36.

464 Cocude-Michel, M. 1963. Les rhynchocéphales et les sauriens des calcaires lithographiques 465 (Jurassique Supérieur) d'Europe occidentale. Nouvells Archives du Museum d'Histoire Naturelle de Lyon 7:1-187.

467 Condon, K. 1987. A kinematic analysis of mesokinesis in the Nile monitor (Varanus niloticus). Experimental Biology 47:73-87.

469

470

471

472

473

474

475

476

477 478

Cooper, J.S., and D.F.G Poole. 1973. The dentition and dental tissues of the agamid lizard, Uromastyx. Journal of Zoology 169:85-100 DOI: 10.1111/j.1469-7998.1973.tb04654.x

Cooper, J.S., D.F.G. Poole, and R. Lawson. 1970. The dentition of agamid lizards with special reference to tooth replacement. Journal of Zoology 162:85-98 DOI: 10.1111/j.14697998.1970.tb01259.x

Cost, I.N., K.M. Middleton, K.C. Sellers, M.S. Echols, L.M. Witmer, J.L. Davis, and C.M. Holliday. 2020. Palatal biomechanics and its significance for cranial kinesis in Tyrannosaurus rex. The Anatomical Record 303:999-1017 DOI: 10.1002/ar.24219

D’Amore, D.C. 2015. Illustrating ontogenetic change in the dentition of the Nile monitor lizard, Varanus niloticus: a case study in the application of geometric morphometric methods for 
479

480

481

482

483

484

485

486

487

488

489

490

491

492

493

494

495

496

497

498

499

500

501

the quantification of shape-size heterodonty. Journal of Anatomy 226:403-419 DOI:

10.1111/joa.12293

Daugherty, C.H., and A. Cree. 1990. Tuatara: a survivor from the dinosaur age. New Zealand Geographic 6:66-86.

Davit-Béal, T., A.S. Tucker, and J-Y. Sire. 2009. Loss of teeth and enamel in tetrapods: fossil record, genetic data and morphological adaptations. Journal of Anatomy 214:477-501 DOI: $10.1111 / \mathrm{j} .1469-7580.2009 .01060$

D’Emic, M.D., P.M. O’Connor, T.R. Pascucci, J.N. Gavras, E. Mardakhayava, and E.K. Lund. 2019. Evolution of high tooth replacement rates in theropod dinosaurs. PLOS ONE $14: \mathrm{e} 0224734$.

Dosedělová, H., K. Štěpánkova, T. Zikmund, H. Lesot, J. Kaiser, K. Novotny, J. Štembírek, Z. Knotek, O. Zahradníček, and M. Buchtova. 2016. Age-related changes in the tooth-bone interface area of acrodont dentition in the chameleon. Journal of Anatomy 229:356-368 DOI: $10.1111 /$ joa. 12490

Dumont, E.R., and A. Herrel. 2003. The effects of gape angle and bite point on bite force in bats. Journal of Experimental Biology 206:2117-2123.

Edmund, A.G. 1960. Tooth replacement phenomena in the lower vertebrates. Royal Ontario Museum, Life Sciences Division, Contribution 52:1-190.

Edmund, A.G., 1962. Sequence and rate of tooth replacement in the crocodilia. Contributions to the Life Science Division of the Royal Ontario Museum 52:1-42.

Erickson, G.N., A.K. Lappin, and K.A. Vliet. 2003. The ontogeny of bite-force performance in the American alligator (Alligator mississippiensis). Journal of Zoology 260:317-327 DOI: $10.1017 / \mathrm{S} 0952836903003819$ 
502 Erickson, G.M., A.K. Lappin, T. Parker, and K.A. Vliet. 2004. Comparison of bite-force

503

504

505

506

507

508

509

510

511

512

513

514

515

516

517

518

519

520

521

522

523 performance between long-term captive and wild American alligators (Alligator mississippiensis). Journal of Zoology 262:21-28.

Estes, R. 1975. Lower vertebrates from the Fort Union Formation, Late Paleocene, Big Horn Basin, Wyoming. Herpetologica 31:365-385.

Estes, R., and E.E. Williams. 1984. Ontogenetic variation in the molariform teeth of lizards. Journal of Vertebrate Paleontology 4:96-107.

Evans, S.E. 1980. The skull of a new eosuchian reptile from the Lower Jurassic of South Wales. Zoological Journal of the Linnean Society 70:203-264.

Evans, S.E. 1985. Tooth replacement in the Lower Jurassic lepidosaur Gephyrosaurus bridensis. Neues Jahrbuch für Geologie und Paläontologie-Monatshefte 1985:411-420.

Evans, S.E. 1991. A new lizard-like reptile (Diapsdia: Lepidosauromorpha) form the Middle Jurassic of England. Zoological Journal of the Linnean Society 103:391-412.

Evans, S.E. 2008. The skull of lizards and the tuatara. In: Gans, C. and A.S. Gaunt (eds.) Biology of the Reptilia Volume 20: The Skull of Lepidosauria pp. 1-347. Ithaca, New York.

Evans, S.E., and M. Borsuk-Białynicka. 2009. A small lepidosauromorph reptile from the Early Triassic of Poland. Palaeontologia Polonica 65:179-202.

Evans, S.E., and G.D. Sanson. 1998. The effect of tooth shape on the breakdown of insects. Journal of Zoology 246:391-400.

Fabre, A-C., D.V. Andrade, K. Huyghe, R. Cornette, and A. Herrel. 2014. Interrelationships between bones, muscles, and performance: biting in the lizard Tupinambis merianae. Evolutionary Biology 41:518-527. 
524 Fraser, N.C. and G.M. Walkden. 1983. The ecology of a Late Triassic reptile assemblage from 525 Gloucestershire, England. Palaeogeology, Palaeoclimatology, Palaeoecology 42: 342-

526 365.

527 Frazzetta, T.H. 1962. A functional consideration of cranial kinesis in lizards. Journal of 528 Morphology 111:287-319.

529

530

531

532

533

534

535

536

537

538

539

540

541

542

543

544

Gans, C. 1960. Studies on amphisbaenids (Amphisbaenia, Reptilia): 1. A taxonomic revision of the Trogonophinae, and a functional interpretation of the amphisbaenid adaptive pattern. Bulletin of the American Museum of Natural History 119:129-204.

Gans, C., and R. Montero. 2008. An atlas of amphisbaenian skull anatomy. Biology of the Reptilia 21:621-738.

Gaengler, P. 2000. Evolution of tooth attachment in lower vertebrates to tetrapods. In: Teaford, M.F., M.M. Smith, and M.W.J. Ferguson (eds.) Development, Function and Evolution of Teeth. Cambridge University Press.

Gorniak, G.C., H.I. Rosenberg, and C. Gans. 1982. Mastication in the tuatara, Sphenodon punctatus (Reptilia: Rhynchocephalia): structure and activity of the motor system. Journal of Morphology 171:321-353.

Gow, C.E. 1977. Tooth function and succession in the Triassic reptile Procolophon trigoniceps. Palaeontology 20:695-704.

Greene, H.W. 1982. Dietary and phenotypic diversity in lizards: why are some organisms specialized? In: Mossakowski, D. and G. Roth (eds.), Environmental Adaptation and Evolution, pp. 107-128. New York City: New York. 
545 Handrigan, G.R., and J.M. Richman. 2010. Autocrine and paracrine Shh signaling are necessary

546 for tooth morphogenesis, but not tooth replacement in snakes and lizards (Squamata).

547 Developmental Biology 337:171-186 DOI: 10.1016/j.ydbio.2009.10.020

548 Haridy, Y. 2018. Histological analysis of post-eruption tooth wear adaptations, and ontogenetic

549 changes in tooth implantation in the acrodontan squamate Pogona vitticeps. PeerJ

$550 \quad$ 6:e5923 DOI: $10.7717 /$ peerj.5923

551 Haridy, Y., A.R. LeBlanc, and R.R. Reisz. 2018. The Permian reptiles Opisthodontosaurus

552 carrolli: a model for acrodont tooth replacement and dental ontogeny. Journal of

553 Anatomy 232:372-382 DOI: 10.1111/joa.12754

554 Herrel, A., L. Spithoven, R. Van Damme, and F. De Vree. 1999. Sexual dimorphism of head size

555 in Gallotia galloti: testing the niche divergence hypothesis by functional analyses.

$556 \quad$ Functional Ecology 13:289-297.

557 Herrel, A., E. de Grauw, and J.A. Lemos-Espinal. 2001. Head shape and bite performance in 558 xenosaurid lizards. Journal of Experimental Zoology 290:101-107.

559 Herrel, A., J.J. Meyers, and B. Vanhooydonck. 2001. Correlations between habitat use and body

560 shape in a phrynosomatid lizard (Urosaurus ornatus): a population-level analysis.

561 Biological Journal of the Linnean Society 74:305-314.

562 Herrel, A., L.D. McBrayer, and P.M. Larson. 2007. Functional basis for sexual differences in 563

564 bite force in the lizard Anolis carolinensis. Biological Journal of the Linnean Society

565 91:111-119.

Herrel, A., J.A. Moore, E.M. Bredeweg, and N.J. Nelson. 2010. Sexual dimorphism, body size, 566 bite force and male mating success in tuatara. Biological Journal of the Linnean Society 567 100:287-292. 
568 Herrel, A., R. Van Damme, B. Vanhooydonck, and F. De Vree. 2001. The implications of bite 569 performance for diet in two species of lacertid lizards. Canadian Journal of Zoology $570 \quad 79: 662-670$.

571 Herrel, A., J.A. Moore, E.M. Bredeweg, and N.J. Nelson. 2010. Sexual dimorphism, body size, 572 and bite force and male mating success in tuatara. Biological Journal of the Linnean Society 100:287-292.

574 Husak, J.F., A.L. Lappin, and R.A. Van Den Bussche. 2009. The fitness advantage of a high575 performance weapon. 2009. The fitness advantage of a high-performance weapon. Biological Journal of the Linnean Society 96:840-845.

577 Husak, J.F., A.K. Lappin, S.F. Fox, and J.A. Lemos-Espinal. 2006. Bite force performance 578 579 predicts dominance in male venerable collared lizards (Crotaphytus antiquus). Copeia

580

581

582

583

584

585 586 2006:301-306.

Huyghe, K., B. VanHooydonck, H. Sheers, M. Molina-Borja, and R. Van Damme. 2005. Morphology, performance and fighting capacity in male lizards, Gallotia galloti. Functional Ecology 19:800-807.

Iordansky, N.N. 1990. Evolution of cranial kinesis in lower tetrapods. Netherlands Journal of Zoology 40:32-54.

Jenkins, K.M, M.E.H. Jones, T. Zikmund, A. Boyde, and J.D. Daza. 2017. A review of tooth implantation among rhynchocephalians (Lepidosauria). Journal of Herpetology 51:300306 DOI: $10.1670 / 16-146$

Jones, M.E.H. 2006. Tooth diversity and function in the Rhynchocephalia. In: P.M. Barrett \& S.E. Evans (eds.), Ninth International Symposium on Mesozoic Terrestrial Ecosystems and Biota, pp. 55-58. London, UK. 
591 Jones, M.E.H. 2008. Skull shape and feeding strategy in Sphenodon and other Rhynchocephalia 592 (Diapsida: Lepidosauria). Journal of Morphology 269:945-966.

593 Jones, M.E.H. 2009. Dentary tooth shape in Sphenodon and its fossil relatives (Diapsida:

594 Lepidosauria: Rhynchocephalia). Comparative Dental Morphology 13:9-15.

595 Jones, M.E.H., and K.A. Lappin. 2009. Bite-force performance of the last rhynchocephalian 596 (Lepidosauria: Sphenodon). Journal of the Royal Society of New Zealand 39:71-83.

597 Kearney, M., J.A. Maisano, and T. Rowe. 2004. Cranial anatomy of the extinct amphisbaenian

598

599

600

601

602

603

604

605

606

607

608

609

610

611 Rhinerua hatcherii (Squamata, Amphisbaenia) based on high-resolution x-ray computed tomography. Journal of Morphology 264:1-33.

Kieser, J.A., T. Tkatchenko, M.C. Dean, M.E.H. Jones, W. Duncan, and N.J. Nelson. 2009. Microstructure of dental hard tissues and bone in the tuatara dentary, Sphenodon punctatus (Diapsida: Lepidosauria: Rhynchocephalia). Comparative Dental Morphology $13: 80-85$.

Kieser, J.A., L-H. He, M.C. Dean, M.E.H. Jones, W.J. Duncan, M.V. Swain, and N.J. Nelson. 2011. Structure and compositional characteristics of caniniform dental enamel in the tuatara Sphenodon punctatus (Lepidosauria: Rhynchocephalia). New Zealand Dental Journal 107:44-50.

Lailvaux, S.P., A. Herrel, B. VanHooydonck, J.J. Meyers, and D.J. Irschick. 2004. Performance capacity, fighting tactics and the evolution of life-stage male morphs in the green anole lizard (Anolis carolinensis). Proceedings of the Royal Society of London Series B 271:2501-2508 DOI: 10.1098/rspb.2004.2891 
612 Lappin, A.K., and J.F. Husak. 2005. Weapon performance, not size, determines mating success

613 and potential reproductive output in the Collared Lizard (Crotaphytus collaris). The $614 \quad$ American Naturalist 166:426-436.

615 Lappin, A.J., and M.E.H. Jones. 2014. Reliable quantification of bite-force performance requires 616 use of appropriate biting substrate and standardization of bite out-lever. Journal of 617 Experimental Biology 217:4303-4312 DOI: 10.1242/jeb.106385

618 Lappin, A.K., P.S. Hamilton, and B.K. Sullivan. 2006. Bite-force performance and head shape in 619 a sexually dimorphic crevice-dwelling lizard, the common chuckwalla [Sauromalus ater $620 \quad$ (=obesus)]. Biological Journal of the Linnean Society 88:215-222.

621 LeBlanc, A.R.H., and R.R. Reisz. 2013. Periodontal ligament, cementum, and alveolar bone in 622 623 the oldest herbivorous tetrapods, and their evolutionary significance. PLoS ONE 8: e74697 DOI:10.1371/journal.pone.0074697

624 LeBlanc, A.R.H., and R.R. Reisz. 2015. Patterns of tooth development and replacement in the 625 captorhinid reptiles: a comparative approach for understanding the origin of multiple 626 tooth rows. Journal of Vertebrate Paleontology 35: e919928.

627 LeBlanc, A.R.H., R.R. Reisz, K.S. Brink, and F. Abdala. 2016. Mineralized periodontia in 628 extinct relatives of mammals shed light on the evolutionary history of mineral homeostasis in periodontal tissue maintenance. Journal of Clinical Periodontology 43:323-332. tooth attachment versus tooth implantation: a case study using dinosaur, crocodilian, and mammal teeth. Journal of Vertebrate Paleontology 37: e1354006. 
634 Lenz, S. 2004. Varanus niloticus. In: Pianka, E.R. and D.R. King (eds.), Varanoid Lizards of the 635 World pp. 133-138. Bloomington, Indiana.

636 Longrich, N.R., J. Vinther, R.A. Pyron, D. Pisani, and J.A. Gauthier. 2015. Biogeography of 637 worm lizards (Amphisbaenia) driven by end-Cretaceous mass extinction. Proceedings of 638 the Royal Society B 282:20143034.

639 Losos, J.B. and H.W. Greene. 1998. Ecological and evolutionary implications of diet in monitor 640 lizards. Biological Journal of the Linnean Society 35:379-407.

641 Lucas, P.W. and D.A. Luke. 1984. Chewing it over: basic principles of food breakdown. In:

642 Chivers, D.J., B.A. Wood, and A. Bilsborough (eds.) Food Acquisition and Processing in 643 Primates pp. 283-302. New York City, New York.

644 Luiselli, L., G.C. Akani, and D. Capizzi. 1999. Is there any interspecific competition between 645 dwarf crocodiles (Osteolaemus tetraspis) and Nile monitors (Varanus niloticus ornatus)

646 in the swamps of central Africa? A study from southeastern Nigeria. Journal of Zoology

647 247:127-131.

648 MacDougall, M.J., A.R.H. LeBlanc, and R.R. Reisz. 2014. Plicidentine in the Early Permian 649 parareptile Colobomycter pholeter, and its phylogenetic and functional significance

650 among coeval members of the clade. PLoS ONE 9:e96559 DOI:

651 10.1371/journal.pone.0096559

652

Maxwell, E.E., M.W. Caldwell, and D.O. Lamoureux. 2011. The structure and phylogenetic 653 distribution of amniote plicidentine. Journal of Vertebrate Paleontology 31:553-561.

654 McBrayer, L.D., and R.A. Anderson. 2007. Sexual size dimorphisms and bite force in the 655 Norther Alligator Lizard, Elgaria coerulea 41:554-559. 
656 McIntosh, J.E., X. Anderton, L. Flores-de-Jacoby, D.S. Carlson, C.F. Shuler, and T.G.H.

657 Diekwisch. 2002. Caiman periodontium as an intermediate between basal vertebrate 658 ankylosis-type attachment and mammalian "true" periodontium. Microscopy Research $659 \quad$ and Technique 59:449-459.

660 Meyers, J.J., and K.C. Nishikawa. 2000. Comparative study of tongue protrusion in three 661 iguanian lizards, Sceloporus undulates, Psuedotrapelus siniatus, and Chamaeleo 662 jacksonii. Journal of Experimental Biology 203:2833-2849.

663 664 665 666 667 668 669 670 671 672 673 674 675 676 677

Meyers, J.J., K.C. Nishikawa, and A. Herrel. 2018. The evolution of bite force in horned lizards: the influence of dietary specialization. Journal of Anatomy 232:214-226.

Mlot, C. 1997. Return of the tuatara. Science News 152:300-301.

Noble, H.W. 1969. The evolution of the mammal periodontium. In: A.R. Melcher and W.A. Bowen (eds.), The Biology of the Periodontium, pp. 1-26. New York City: New York.

Osborn, J.W. 1984. From reptile to mammal: evolutionary considerations of the dentition with emphasis on tooth attachment. Symposia of the Zoological Society of London 52:549-574.

Picton, D.C.A. 1989. The periodontal enigma: eruption versus tooth support. European Journal of Orthodontics 11:430-439.

Preuschoft, H., W.E. Reif, C. Loitsch, and E. Tepe. 1991. The function of labyrinthodont teeth: big teeth in small jaws. In: N. Schmidt-Kittler and K. Vogel (eds.), Constructional Morphology and Evolution, pp. 151-171. Berlin: Germany.

Rauhut, O.W.M., A.M. Heyng, A. López-Arbarello, and A. Hecker. 2012. A new rhynchocephalian from the Late Jurassic of Germany with a dentition that is unique amongst tetrapods. PLoS ONE 7:e46839 DOI: 10.1371/journal.pone.0046839 
678 Reynoso, V.H. 1998. Huehuecuetzpalli mixtecus gen. et sp. nov: a basal squamate (Reptilia)

679 from the Early Cretaceous of Tepexi de Rodríguez, Central México. Philosophical

680 Transitions of the Royal Society B 353:477-500.

681 Reynoso, V.H. 2000. An unusual sphenodontian (Reptilia: Diapsida) from the Tlayua Formation

682 (Albian), Central Mexico. Journal of Paleontology 74:133-148.

683 Reynoso, V.H. 2003. Growth patterns and ontogenetic variation of the teeth and jaws of the 684 Middle Jurassic sphenodontian Cynosphenodon huizachalensis (Reptilia:

685 Rhynchocephalia). Canadian Journal of Earth Science 40:609-619.

686

687

688

689

690

691

692

693

694

695

696

697

698

Rieppel, O. 1979. A functional interpretation of the varanid dentition (Reptilia, Lacertilia, Varanidae). Gegenbaurs Morphologisches Jahrbuch 125:797-817.

Rieppel, O. 1992. The skull in a hatchling of Sphenodon punctatus. Journal of Herpetology 26:80-84.

Rieppel, O. and L. Labhardt. 1979.Mandibular mechanics in Varanus niloticus (Reptilia: Lacertilia). Herpetologica 35:158-163.

Robb, J. 1977. The Tuatara. New Zealand: Meadowfield.

Robinson, P.L. 1976. How Sphenodon and Uromastyx grow their teeth and use them. Morphology and Biology of Reptiles 3:43-65.

Romer, A.S. 1956. Osteology of the Reptiles. Chicago: University of Chicago Press.

Salomies, L., J. Eymann, I. Khan, and N. Di-Poï. 2019. The alternative regenerative strategy of bearded dragon unveils the key processes underlying vertebrate tooth renewal. eLife 8:e47702. DOI: 10.7554/eLife.47702 
699 Schaerlaeken, V., A. Herrel, P. Aerts, and C.F. Ross. 2008. The functional significance of the 700 lower temporal bar in Sphenodon punctatus. The Journal of Experimental Biology $701 \quad 211: 3908-3914$.

702 Schaerlaeken, V., V. Holanova, R. Boistel, P. Aerts, P. Velensky, I. Rehak, D.V. Andrade, and 703 704 705 Experimental Zoology Part A 317:371-381 DOI: 10.1002/jez.1730

706 707

708

709

710

711

712

713

714

715

716

717

718

719

A. Herrel. 2012. Built to bite: feeding kinematics, bite forces, and head shape of a specialized durophageous lizard, Dracaena guianensis (Teiidae). Journal of

Sellers, K.C., K.M. Middleton, J.L. Davis, and C.M. Holliday. 2017. Ontogeny of bite force in a validated biomechanical model of the American alligator. Journal of Experimental Biology 220:2036-2046.

Simões, T.R., E. Wilner, M.W. Caldwell, L.C. Weinschütz, and A.W.A. Kellner. 2015. A stem acrodontan lizard in the Cretaceous of Brazil revises early lizard evolution in Gondwana. Nature Communications 6:8149.

Simões, T.R., M.W. Caldwell, M. Tałanda, M. Bernardi, A. Palci, O. Vernygora, F. Bernardini, L. Mancini, R.L. Nydam. 2018. The origin of squamates revealed by a Middle Triassic lizard from the Italian Alps. Nature 557:706-711 DOI: 10.1038/s41586-018-0093-3

Smirina, E.M., and N.B. Ananjeva. 2007. Growth layers in bones and acrodont teeth of the agamid lizard Laudakia stoliczkana. Amphibia-Reptilia 28:193-204.

Smith, H.M. 1958. Evolutionary lines in tooth attachment and replacement in reptiles: their possible significance in mammalian dentition. Transactions of the Kansas Academy of Science 61:216-225. 
720 Snyder, A.J., A.R.H. LeBlanc, C. Jun, J.J. Bevitt, and R.R. Reisz. 2020. Thecodont tooth

721

722

723

724

725

726

727

728

729

730

731

732

733

734

735

736

737

738

739

740 attachment andreplacement in bolosaurid parareptiles. PeerJ 8: e9168 DOI: 10.7717/peerj.9168

Sobral, G., T.R. Simões, and R.R. Schoch. 2020. A tiny new Middle Triassic stemlepidosauromorph from Germany: implications for the early evolution of lepidosauromorphs and the Vellberg fauna. Scientific Reports 10:2273 DOI: $10.1038 / \mathrm{s} 41598-020-58883-\mathrm{X}$

Sullivan, R.M. 1985. A new middle Paleocene (Torrejonian) rhineurid amphisbaenian amphisbaenian, Plesiorhineura tsentasi new genus new species, from the San Juan Basin, New Mexico. Journal of Paleontology 59: 1481-1485.

Throckmorton, G.S. 1979. The effect of wear on the cheek teeth and associated dental tissues of the lizard Uromastix aegyptius (Agamidae). Journal of Morphology 160:195-208.

Tseng, Z.J. and W.J. Binder. 2010. Mandibular biomechanics of Crocuta crocuta, Canis lupus, and the late Miocene Dinocrocuta gigantea. Zoological Journal of the Linnean Society 158:683-696.

Valido, A., M. Nogales, and F.E. Medina. 2003. Fleshy fruits in the diet of Canarian lizards Gallotia galloti (Lacertidae) in a xeric habitat of the Island of Tenerife. Journal of Herpetology 37:741-747.

Verwaijen, D., R. Van Damme, and A. Herrel. 2002. Relationships between head size, bite force, and prey handling efficiency and diet in two sympatric lacertid lizards. Functional Ecology 16:842-850. 
741 Whiteside, D.I. 1986. The head skeleton of the Rhaetian sphenodontid Diphydontosaurus avonis

742 gen. et sp. nov., and the modernising of a living fossil. Philosophical Transactions of the

$743 \quad$ Royal Society of London B 312:379-430.

744 Wroe, S., C. McHenry, and J. Thomason. 2005. Bite club: comparative bite force in big biting

745 mammals and the prediction of predatory behaviour in fossil taxa. Proceedings of the

$746 \quad$ Royal Society B 272:619-625.

747 Yatkola, D.A. 1976. Mid-Miocene lizards from western Nebraska. Copeia 1976:645-654.

748 Zaher, H., and O. Rieppel. 1999. Tooth implantation and replacement in squamates, with special

749 reference to mosasaur lizards and snakes. American Museum Novitates 3271:1-19.

750 


\section{$751 \quad$ Figure Legend}

752 Figure 1: Simplified phylogeny of Lepidosauria from Gauthier et al. (2012). Orange

753 branches indicate acrodont ankylosis. Phylogeny is based on a morphological dataset and

754 parsimony analysis.

755 Figure 2: Acrodont ankylosis as seen in two species of Acrodonta (A \& B) and a

756 rhynchocephalian (C) and pleurodont ankylosis (D). A) the chameleon Fercifer oustaleti

757 YPM R 1214, B) the agamid Agama agama YPM R 17936, and C) the rhynchocephalian

758 Sphenodon punctatus YPM R 10647. D) Pleurodont tooth implantation as seen in Ctenosaura sp.

759 YPM R 11060.

760 Figure 3: Acrodont vs. Pleurodont bite force (SVL). A) Linear regression (grey line) of log-

761 transformed snout-vent length (SVL) and bite force. Acrodonts indicated by red datapoints and

762 pleurodonts indicated by blue datapoints. B) Boxplot of the distributions of snout-vent length

763 normalized bite force (SVL-NBF), calculated as the residual values from the linear regression in

764 (A), overlain with residual values as datapoints. C) Breakdown of SVL-NBF values show in (B)

765 by diet. D) Breakdown of SVL-NBF values shown in (B) by family and separated based on tooth

766 implantation (acrodonts in red, pleurodonts in blue).

767 Figure 4: Acrodont vs. Pleurodont bite force (HD). A) Linear regression (grey line) of log-

768 transformed head depth (HD) and bite force. Acrodonts indicated by red datapoints and

769 pleurodonts indicated by blue datapoints. B) Boxplot of the distributions of head depth

770 normalized bite force (HD-NBF), calculated as the residual values from the linear regression in

771 (A), overlain with residual values as datapoints. C) Breakdown of HD-NBF values show in (B)

772 by diet. D) Breakdown of HD-NBF values shown in (B) by family and separated based on tooth

773 implantation (acrodonts in red, pleurodonts in blue). 
774 Figure 5: Number of species analyzed for bite force by family, colored by tooth

775 implantation.

776 
Figure 1

Simplified phylogeny of Lepidosauria from Gauthier et al. (2012).

Orange branches indicate acrodont ankylosis. Phylogeny is based on a morphological dataset and parsimony analysis.

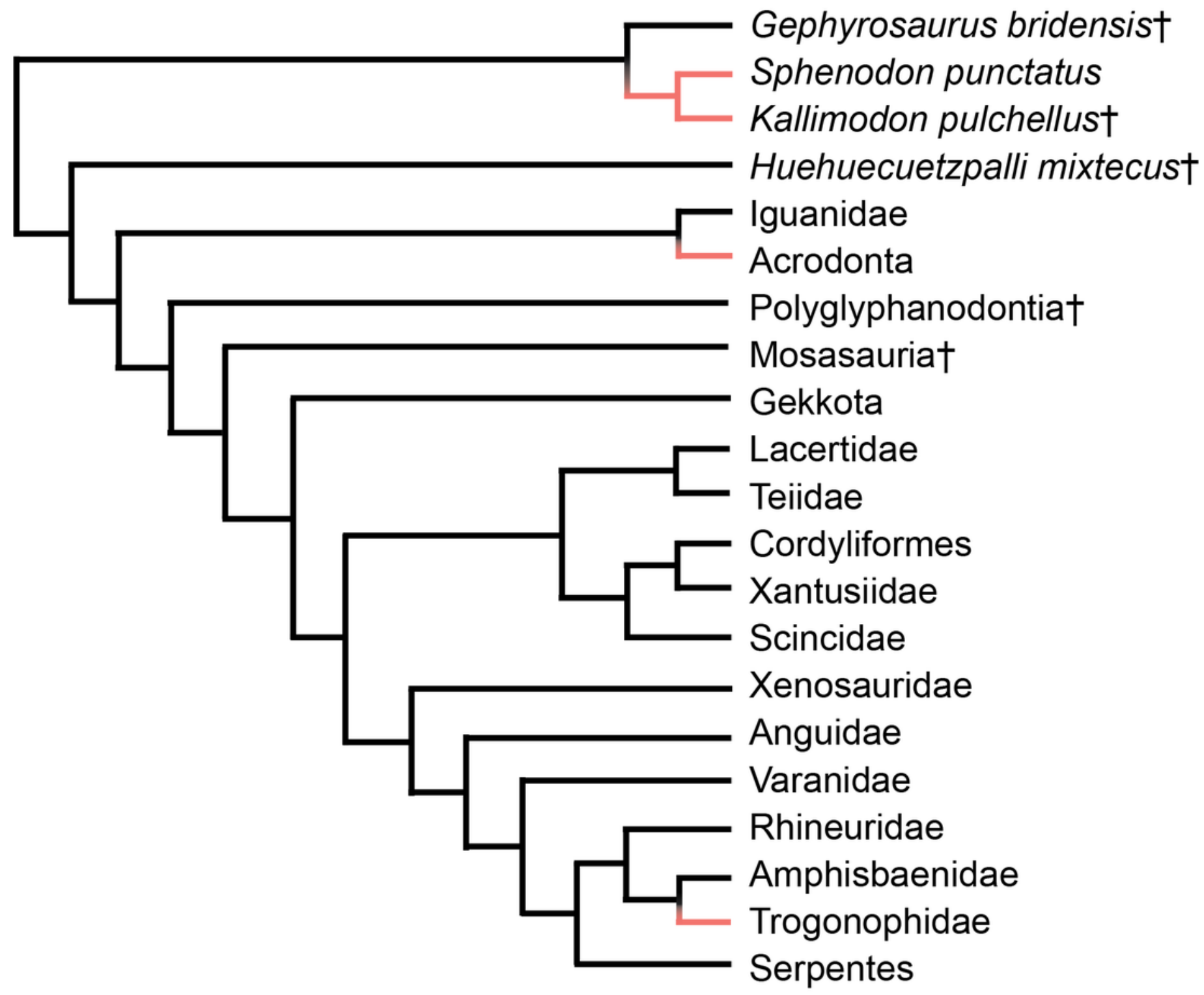


Figure 2

Acrodont ankylosis as seen in two species of Acrodonta $(A \& B)$ and a rhynchocephalian (C) and pleurodont ankylosis (D).

A) the chameleon Fercifer oustaleti YPM R 1214, B) the agamid Agama agama YPM R 17936, and C) the rhynchocephalian Sphenodon punctatus YPM R 10647. D) Pleurodont tooth implantation as seen in Ctenosaura sp. YPM R 11060. 

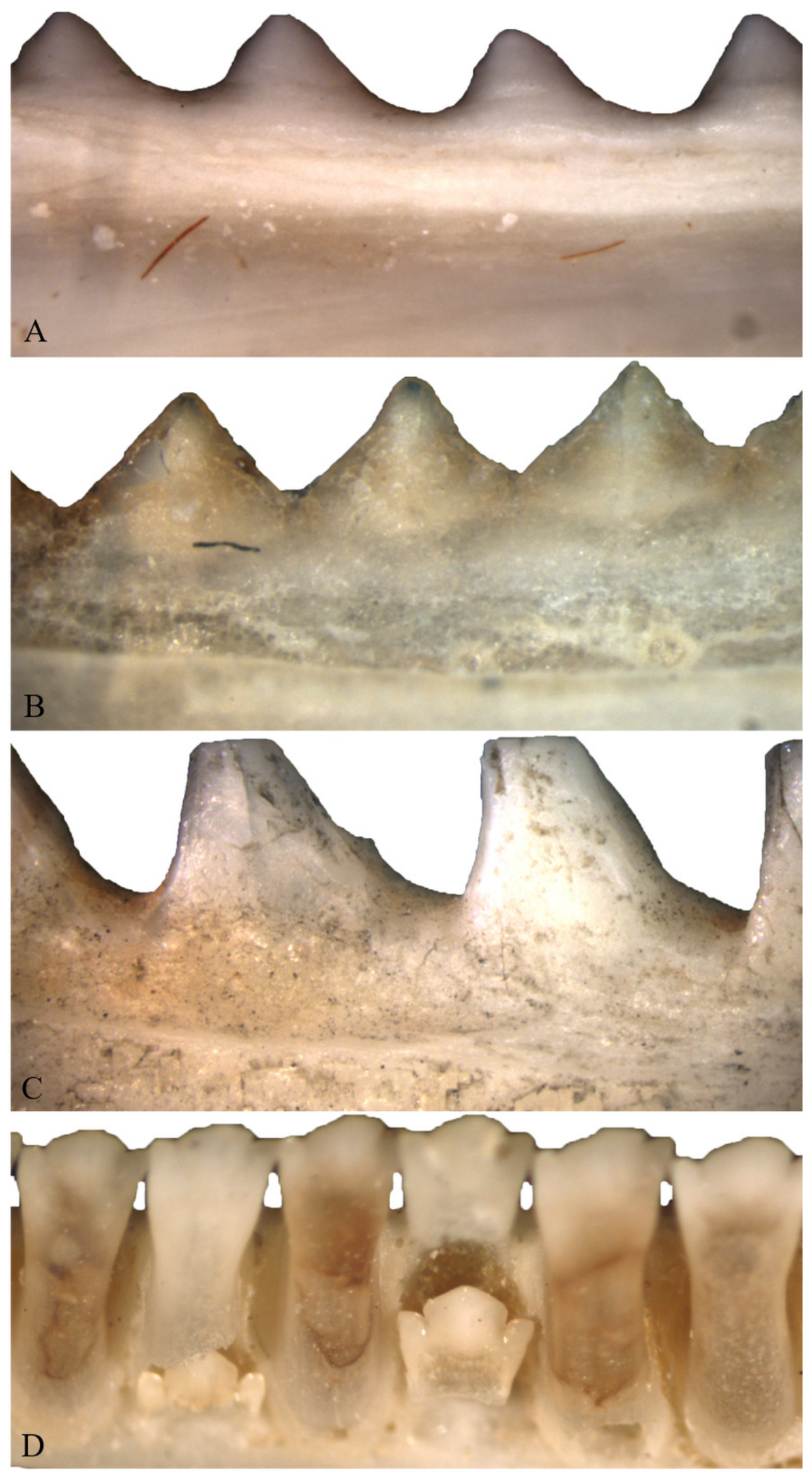


\section{Figure 3}

Acrodont vs. Pleurodont bite force (SVL).

A) Linear regression (grey line) of log-transformed snout-vent length (SVL) and bite force. Acrodonts indicated by red datapoints and pleurodonts indicated by blue datapoints. B) Boxplot of the distributions of snout-vent length normalized bite force (SVL-NBF), calculated as the residual values from the linear regression in $(A)$, overlain with residual values as datapoints. C) Breakdown of SVL-NBF values show in (B) by diet. D) Breakdown of SVL-NBF values shown in (B) by family and separated based on tooth implantation (acrodonts in red, pleurodonts in blue). 

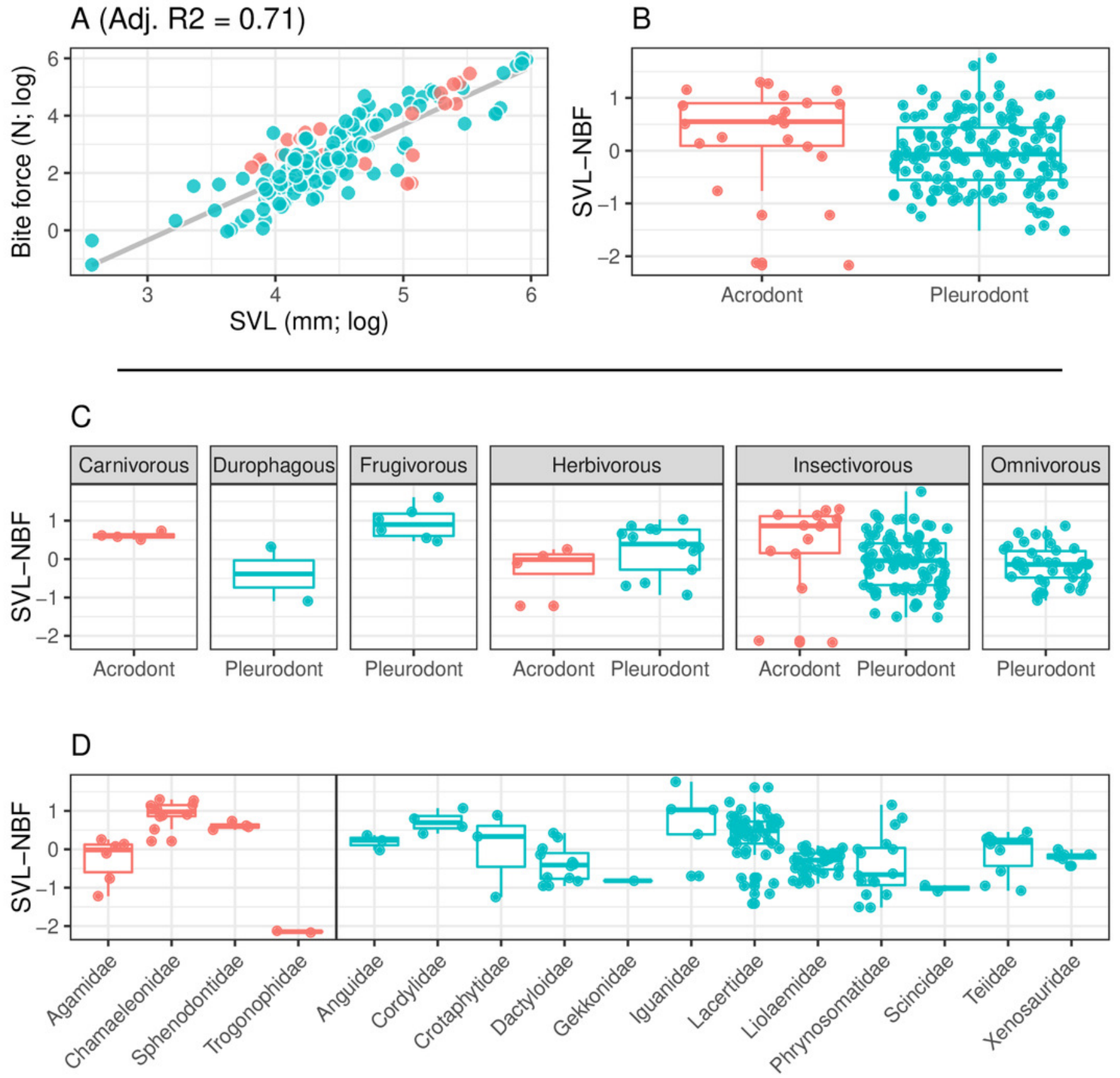


\section{Figure 4}

Acrodont vs. Pleurodont bite force (HD).

A) Linear regression (grey line) of log-transformed head depth (HD) and bite force. Acrodonts indicated by red datapoints and pleurodonts indicated by blue datapoints. B) Boxplot of the distributions of head depth normalized bite force (HD-NBF), calculated as the residual values from the linear regression in (A), overlain with residual values as datapoints. C) Breakdown of HD-NBF values show in (B) by diet. D) Breakdown of HD-NBF values shown in (B) by family and separated based on tooth implantation (acrodonts in red, pleurodonts in blue). 
A (Adj. R2 = 0.69)

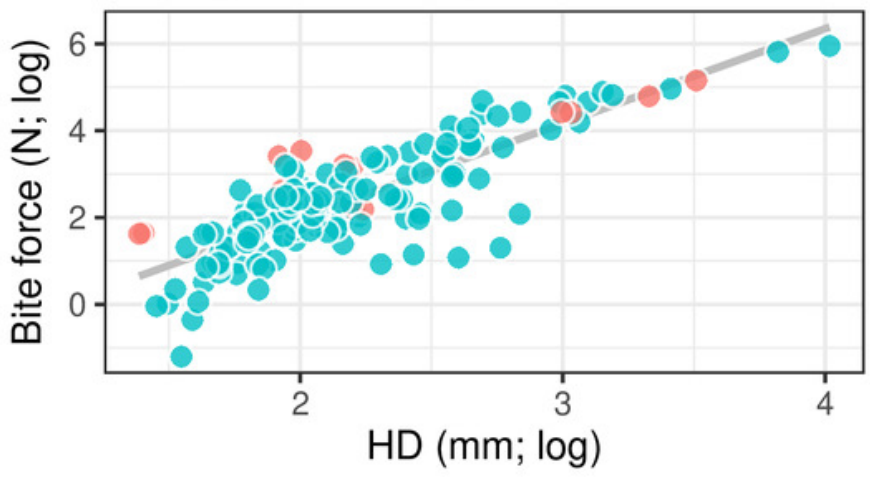

B

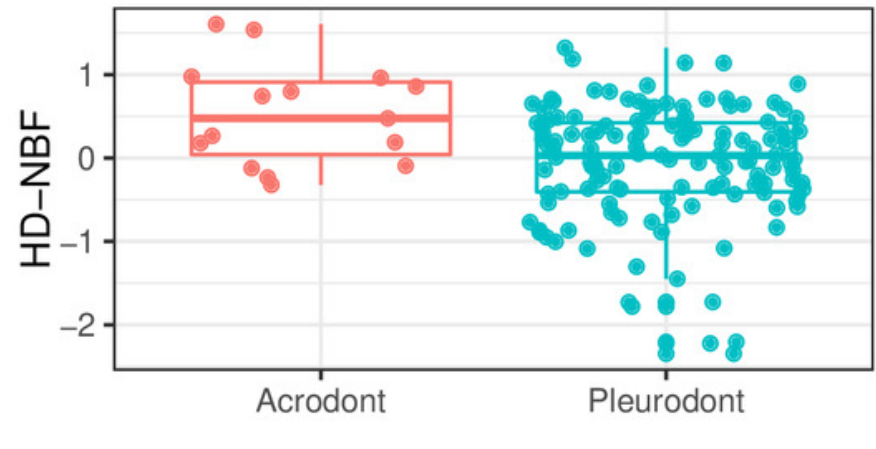

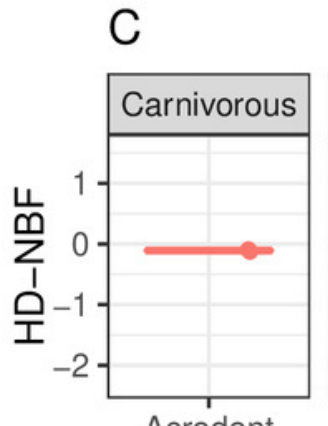

Acrodont

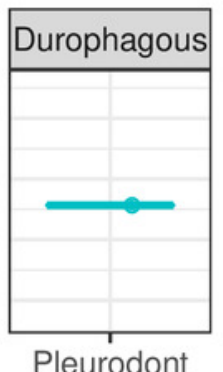

Pleurodont

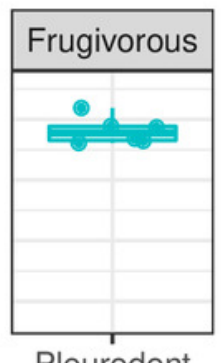

Pleurodont

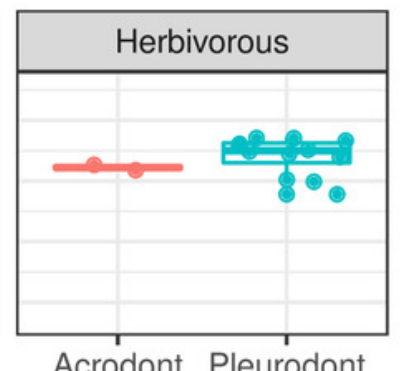

Acrodont Pleurodont

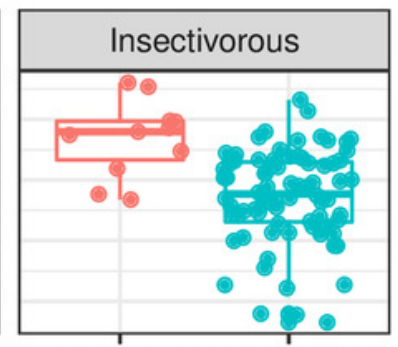

Acrodont Pleurodont

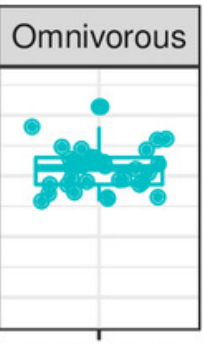

Pleurodont

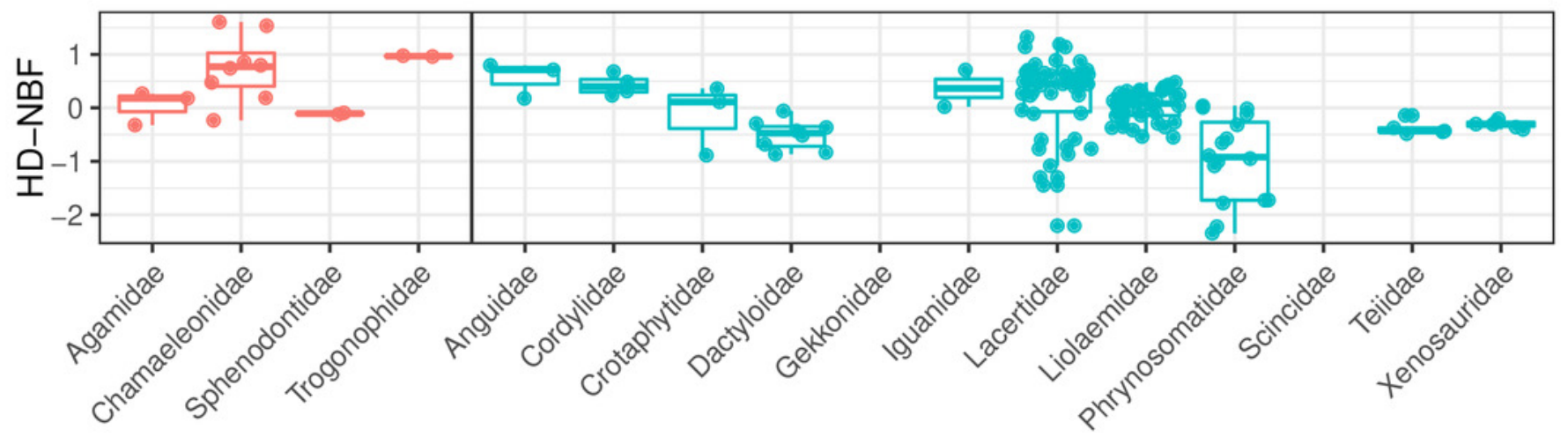


Figure 5

Number of species analyzed for bite force by family, colored by tooth implantation.

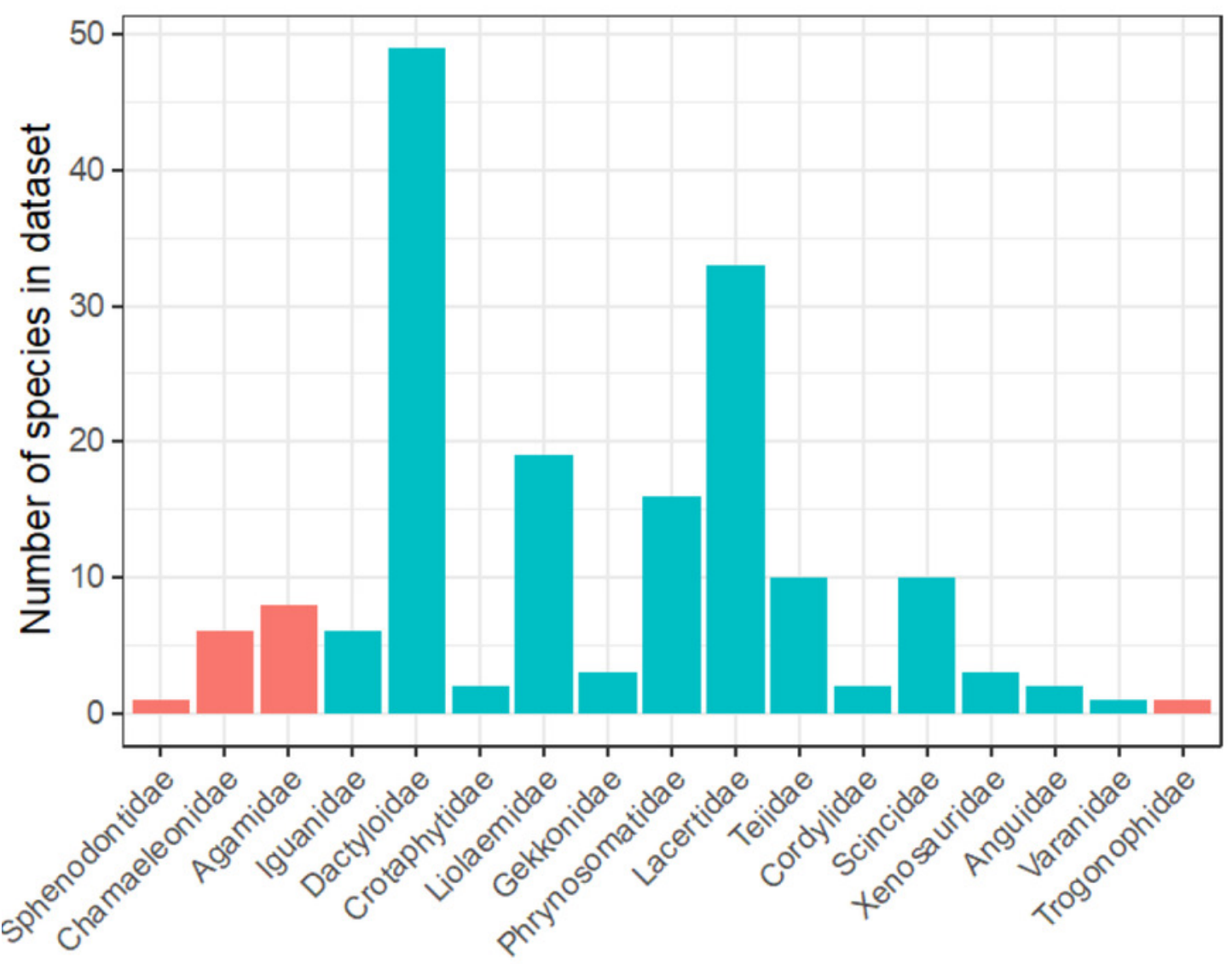

Acrodont

Pleurodont

Families 